\title{
Downregulation of microRNA-95-3p suppresses cell growth of osteosarcoma via CDKN1A/p21 expression
}

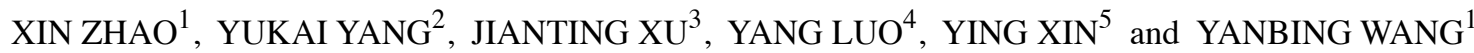 \\ ${ }^{1}$ Department of Orthopedics, The Second Hospital of Jilin University, Changchun, Jilin; ${ }^{2}$ Department of Orthopedics, \\ Tongliao Kezuozhongqi People's Hospital, Neimenggu; ${ }^{3}$ Cancer Center, The First Hospital of Jilin University, \\ Changchun, Jilin; ${ }^{4}$ Department of Orthopaedics, General Hospital of Chinese PLA, Beijing; ${ }^{5}$ Key Laboratory \\ of Pathobiology, Ministry of Education, Jilin University, Changchun, Jilin, P.R. China
}

Received February 19, 2017; Accepted July 20, 2017

DOI: $10.3892 /$ or.2017.6065

\begin{abstract}
The purpose of the present study was to examine the function of microRNA-95-3p on cell growth of osteosarcoma and to investigate its mechanism. Compared to healthy controls, the serum expression of microRNA-95-3p was effectively upregulated in patients with osteosarcoma. MicroRNA-95-3p expression in patients with osteosarcoma had significant association with clinical stage. Downregulation of microRNA-95-3p expression suppressed cell growth, induced apoptosis, increased caspase- 3 and caspase- 9 activities and $\mathrm{Bax} / \mathrm{Bcl}-2$ protein expression in osteosarcoma cells. The anticancer effects of microRNA-95-3p on cell growth of osteosarcoma cell suppressed TGF- $\beta$ and $\mathrm{p}-\mathrm{Smad} 2$ protein expression, induced $\mathrm{p} 21$ protein expression and suppressed cyclin D1 protein expression in osteosarcoma cells. Whereas, overexpression of microRNA-95-3p increased cell growth, and inhibited apoptosis of osteosarcoma cells through TGF- $\beta /$ CDKN1A/p21/cyclin D1 expression. After promotion of TGF- $\beta$, the anticancer effects of microRNA-95-3p were effectively reversed in osteosarcoma cells. Taken together, our results demonstrate that downregulation of microRNA95-3p suppresses cell growth of osteosarcoma via CDKN1A/ p21 expression.
\end{abstract}

\section{Introduction}

Osteosarcoma is the most common primary malignant bone tumor, in which sarcoma cells of malignant proliferation generate neoplastic osteoid or immature bones directly (1). Its histological characteristic is that proliferative spindle tumor cells generate osteoid matrix or immature bones directly (2). Microscopically, it can be observed that there

Correspondence to: Dr Yanbing Wang, Department of Orthopedics, The Second Hospital of Jilin University, 218 Ziqiang Street, Nanguan, Changchun, Jilin 130000, P.R. China

E-mail: drwyb@163.com

Key words: microRNA-95-3p, osteosarcoma, p21, TGF- $\beta$ are many tumor cells with various sizes and shapes and nuclei, small multinuclear giant cells, spindle cells, immature chondrocytes and malignant osteoblasts which are dark with a large nucleus (3). Almost all metastases of osteosarcoma occur in lungs via blood and the minority of its metastases occurs in visceral organs such as brain and kidneys and via lymph nodes (4).

MicroRNAs (miRNAs) are a type of non-coding RNAs with regulatory function and a length of approximately 20-25 nucleotides, which identify target mRNAs according to the principle of complementary base pairing and guide silencing complex to degrade target mRNAs or repress translation of mRNAs (5). Increasing studies found that miRNAs played an important role in specific cellular processes such as cell differentiation, morphosis and neoplasia (6). In human cancer, a miRNA can be an oncogene or a cancer suppressor gene in the process of tumorigenesis.

Recent research showed that microRNAs (miRNAs) played an important role in tumorigenesis and tumor development, which provided a new idea for diagnosis and treatment of tumors (7). miRNAs are a type of recently discovered non-coding microRNAs with a length of 22-28 nucleotides, which widely exist in eucaryon. By complete or partial complementary pairing with and binding to the target gene mRNA 3'-UTR, miRNAs cause degradation of target miRNA or translational suppression to regulate the expression of target genes, affecting biological behavior such as cell proliferation, invasion, differentiation and apoptosis. Unlike siRNAs, miRNAs have multiple target genes. As endogenous RNA interference is triggered, miRNAs regulate cells which are closer to a physiological level instead of regulation through a simple gene knockout.

The p21-activated kinase 7 (PAK7, also known as PAK5) is a recently discovered protein involving in cell apoptosis and a newly found member of the family of p21-activated kinases (PAKs) (8). p21-activated kinases are a kind of evolutionarily conserved serine/threonine protein kinases which participate in regulation of many important biological activities such as regulation of cytoskeleton, cell cycle, cell apoptosis, gene transcription and angiogenesis and especially play an important biological role in tumorigenesis, tumor invasion and metastases (9). 


\section{Materials and methods}

Ethics statement, patients, and samples. Peripheral blood of OS patients and normal volunteers were collected at The Second Hospital of Jilin University, (Changchun, China). Serum was collected after $1000 \mathrm{xg}$ for $10 \mathrm{~min}$ and saved at $-70^{\circ} \mathrm{C}$. The follow-up protocols were consistent every three months. This study was approved by the ethics committees of The Second Hospital of Jilin University.

Cell lines and human tumor samples. The human osteosarcoma cell line F5M2 was acquired from the American Type Culture Collection (Manassas, VA, USA). F5M2 cells werecultured with RPMI-1640 medium (Gibco Life Technologies, Gaitherburg, MD, USA) supplemented with $10 \%$ fetal bovine serum (Gibco Life Technologies) and penicillin $(100 \mathrm{U} / \mathrm{ml}) /$ streptomycin $(100 \mu \mathrm{g} / \mathrm{ml})$ at $37^{\circ} \mathrm{C}$ in a humidified atmosphere with $5 \% \mathrm{CO}_{2}$.

Real-time RT-PCR analysis. Total RNA was isolated using TRIzol reagent (Invitrogen Life Technologies) and reversetranscribed to cDNA by the RevertAid First Strand cDNA synthesis kit (Fermentas). The level of microRNA-95-3p was quantified by RT-qPCR (ABI Prism 7600) using power SYBR $^{\circledR}$ Green PCR Master Mix (Applied Biosystems). PCR conditions were predenaturation at $95^{\circ} \mathrm{C}$ for $5 \mathrm{~min}$, then $94^{\circ} \mathrm{C}$ for $1 \mathrm{~min}$, annealing at $58^{\circ} \mathrm{C}$ for $30 \mathrm{sec}$ and elongation at $72^{\circ} \mathrm{C}$ for $30 \mathrm{~min}$, for a total of 40 cycles.

MicroRNA reagents. We purchased TGF- $\beta$, microRNA-95-3p, anti-microRNA-95-3p and negative control miRNA mimics from Guangzhou RioboBio (Guangzhou, Guangdong, China). MicroRNA-95-3p, anti-microRNA-95-3p and negative control miRNA mimics were transfected using Lipofectamine 2000 (Gibco Life Technologies).

Cell proliferation and apoptosis assays. Cells were seeded onto 96-well plates and treated with methylthiazolyldiphenyltetrazolium bromide (MTT) assay (Sigma-Aldrich, St. Louis,

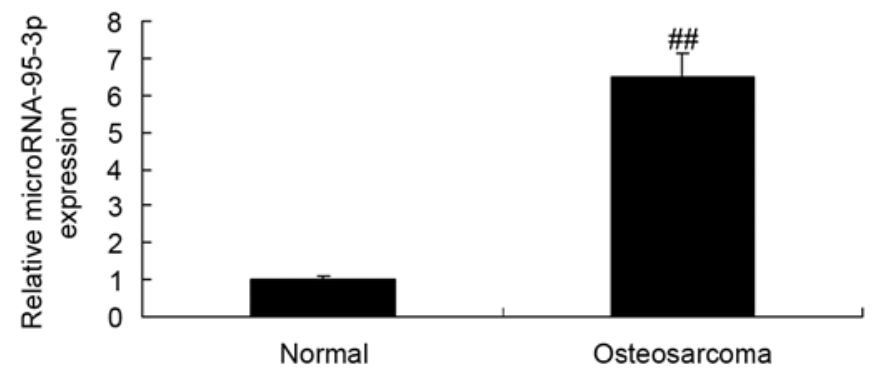

Figure 1. Serum expression of microRNA-95-3p. Normal, normal group; osteosarcoma, osteosarcoma patients. ${ }^{\# \#} \mathrm{P}<0.01$ compared with normal group.

MO, USA) for $4 \mathrm{~h}$. DMSO was added into cells with shaking for $20 \mathrm{~min}$. The absorbance was determined at $490 \mathrm{~nm}$ on a microplate spectrophotometer (SpectraMax, Molecular Devices, Sunnyvale, CA, USA).

Cells were seeded onto 6-well plates and stained with Annexin V-FITC/PI Apoptosis Assay (BD Biosciences Pharmingen, San Diego, CA, USA) for $20 \mathrm{~min}$ in the dark. Apoptotic cells were recorded by applying CellQuest Software (BD Biosciences Pharmingen).

Western blotting. Total proteins were extracted from cells using RIPA buffer containing protease inhibitors and phosphatase inhibitors. Equal amounts $(30 \mu \mathrm{g})$ of lysate were separated by $8-10 \%$ SDS-polyacrylamide gel electrophoresis (SDS-PAGE) and then transferred to PVDF membranes (Millipore). Membranes were blocked with 5\% bovine serum albumin (BSA) and incubated with Bax (Cell Signaling Technology), TGF- $\beta$ (Cell Signaling Technology), p-Smad2 (Cell Signaling Technology), p21 (Cell Signaling Technology), cyclin D1 (Cell Signaling Technology) and GAPDH (Cell Signaling Technology) at $4^{\circ} \mathrm{C}$ overnight. Then, membranes was washed with TBST and incubated with HRP secondary antibodies (Cell Signaling Technology) for $1 \mathrm{~h}$ at $37^{\circ} \mathrm{C}$. Protein blank was visualized by ECL Western blotting kit (Millipore).

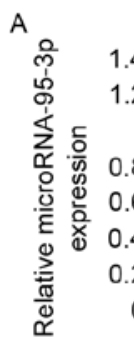

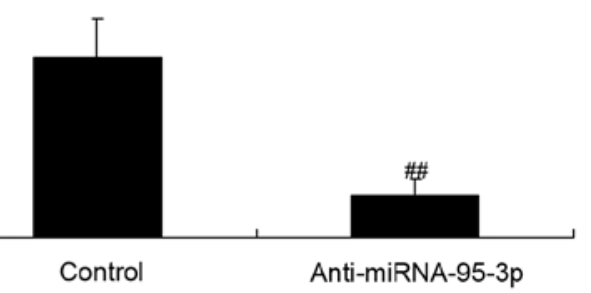

C
B

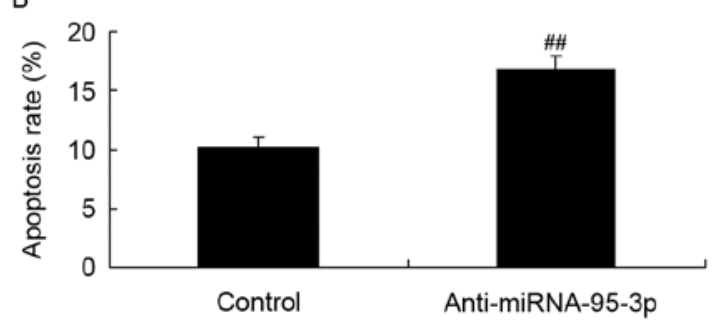

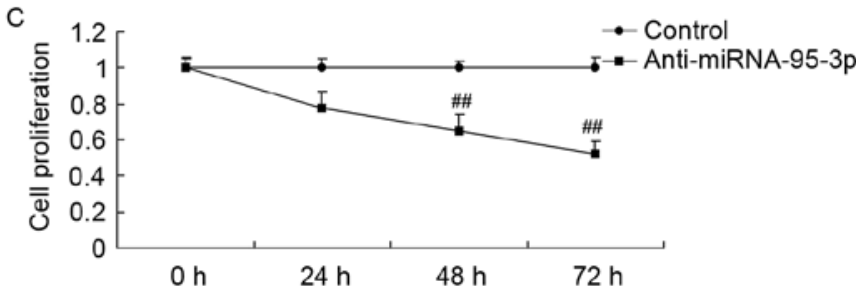

Figure 2. Cell growth and apoptosis of osteosarcoma cells by microRNA-95-3p downregulation. MicroRNA-95-3p expression (A), apoptosis rate (B), and cell growth (C). Control, control group; anti-microRNA-95-3p, anti-microRNA-95-3p mimics group. ${ }^{\# \#} \mathrm{P}<0.01$ compared with control group. 


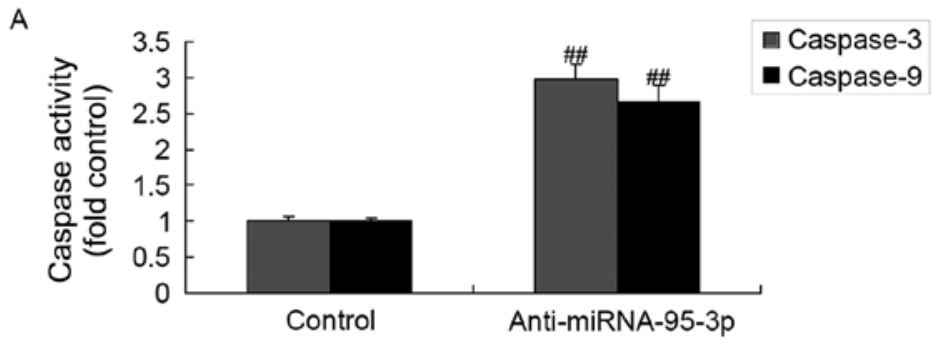

B

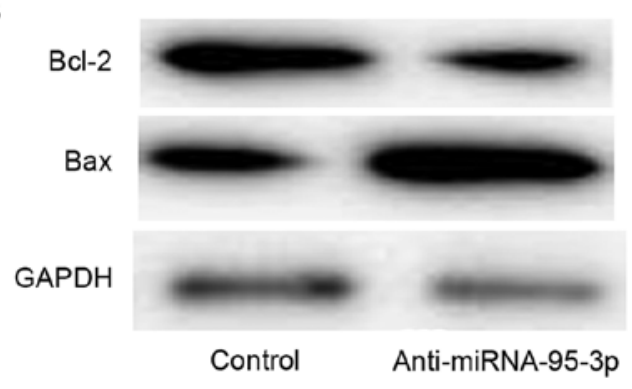

C

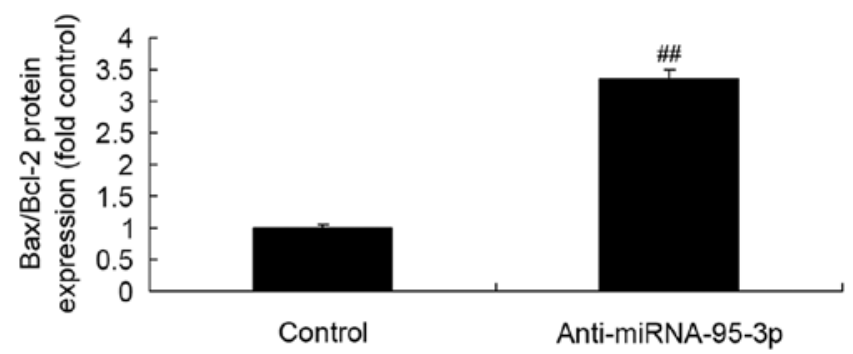

Figure 3. Activity of caspase-3 and caspase- 9 and Bax/Bcl-2 protein expression of osteosarcoma cells by microRNA-95-3p downregulation. Caspase-3/9 activity (A), Bax/Bcl-2 protein expression by western blot assays (B) and statistical analysis of Bax/Bcl-2 protein expression (C). Control, control group; anti-microRNA-95-3p, anti-microRNA-95-3p mimics group. ${ }^{\# \#} \mathrm{P}<0.01$ compared with control group.

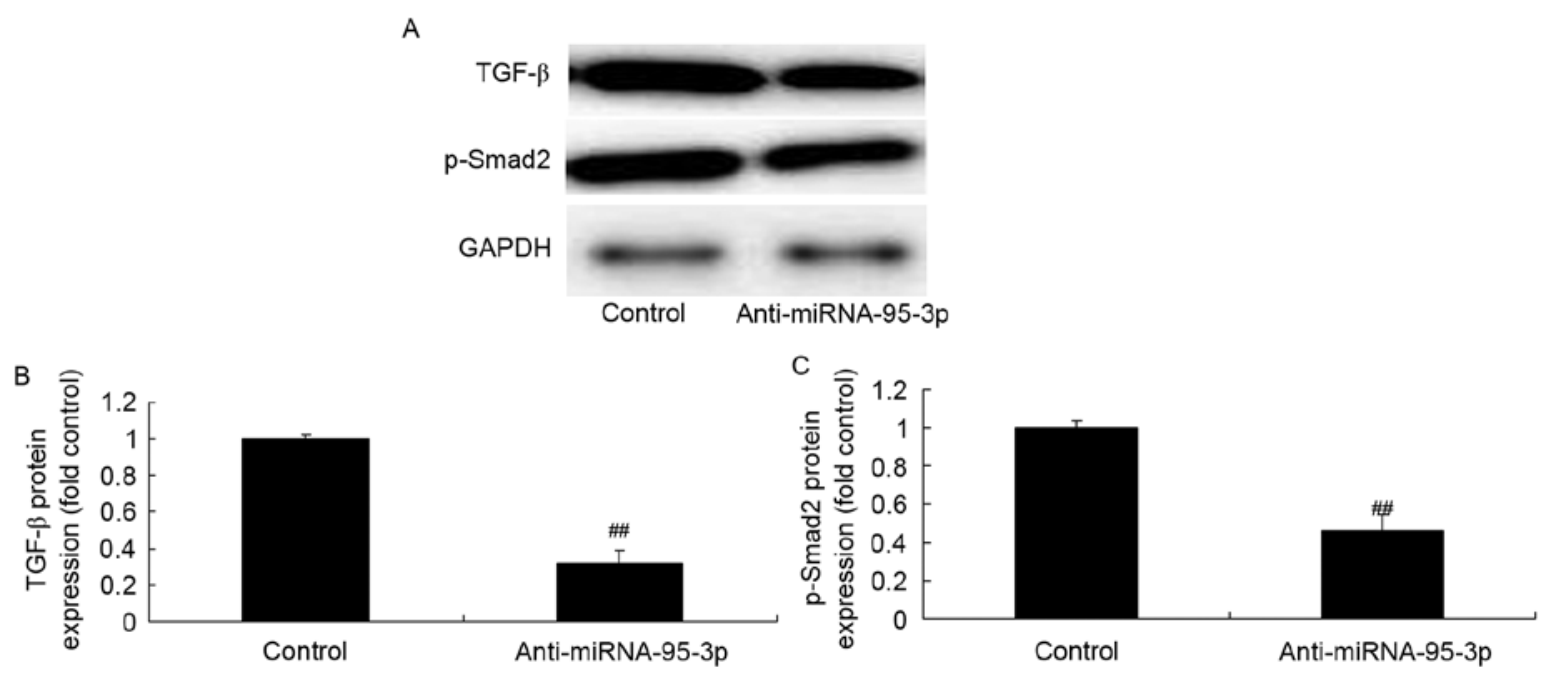

Figure 4. TGF- $\beta$ and Smad2 protein expression of osteosarcoma cells by microRNA-95-3p downregulation. TGF- $\beta$ and p-Smad 2 protein expression by western blot assays (A) and statistical analysis of TGF- $\beta$ and p-Smad2 protein expression (B and C). Control, control group; anti-microRNA-95-3p, anti-microRNA-95-3p mimics group. ${ }^{\# \#} \mathrm{P}<0.01$ compared with control group.

Statistical analyses. Comparisons between two groups were analyzed using the Student's t-test. The data were presented as means \pm SD. A $\mathrm{P}<0.05$ was considered statistically significant.

\section{Results}

Serum expression of microRNA-95-3p. First, we analyzed the serum expression of microRNA-95-3p using Real-time RT-PCR analysis. As shown in Fig. 1, compared to healthy controls, the serum expression of microRNA-95-3p was effectively upregulated in patients with osteosarcoma.

Cell growth and apoptosis of osteosarcoma cells by microRNA-95-3p downregulation. We determined whether microRNA-95-3p downregulation affects on cell growth of osteosarcoma in vitro. MicroRNA-95-3p downregulation significantly inhibited cell proliferation and induced apoptosis level of osteosarcoma (Fig. 2).

Caspase-3 and caspase-9 activities and Bax/Bcl-2 protein expression of osteosarcoma cells by microRNA-95-3p downregulation. Then, we analyzed the mechanism of apoptosis of microRNA-95-3p on osteosarcoma. However, as compared to control group, much larger induction of caspase-3 and caspase- 9 activity, and $\mathrm{Bax} / \mathrm{Bcl}-2$ protein expression were observed by microRNA-95-3p downregulation (Fig. 3).

TGF- $\beta$ and Smad2 protein expression of osteosarcoma cells by microRNA-95-3p downregulation. To examine the regulative effects of microRNA-95-3p on apoptosis of osteosarcoma, 


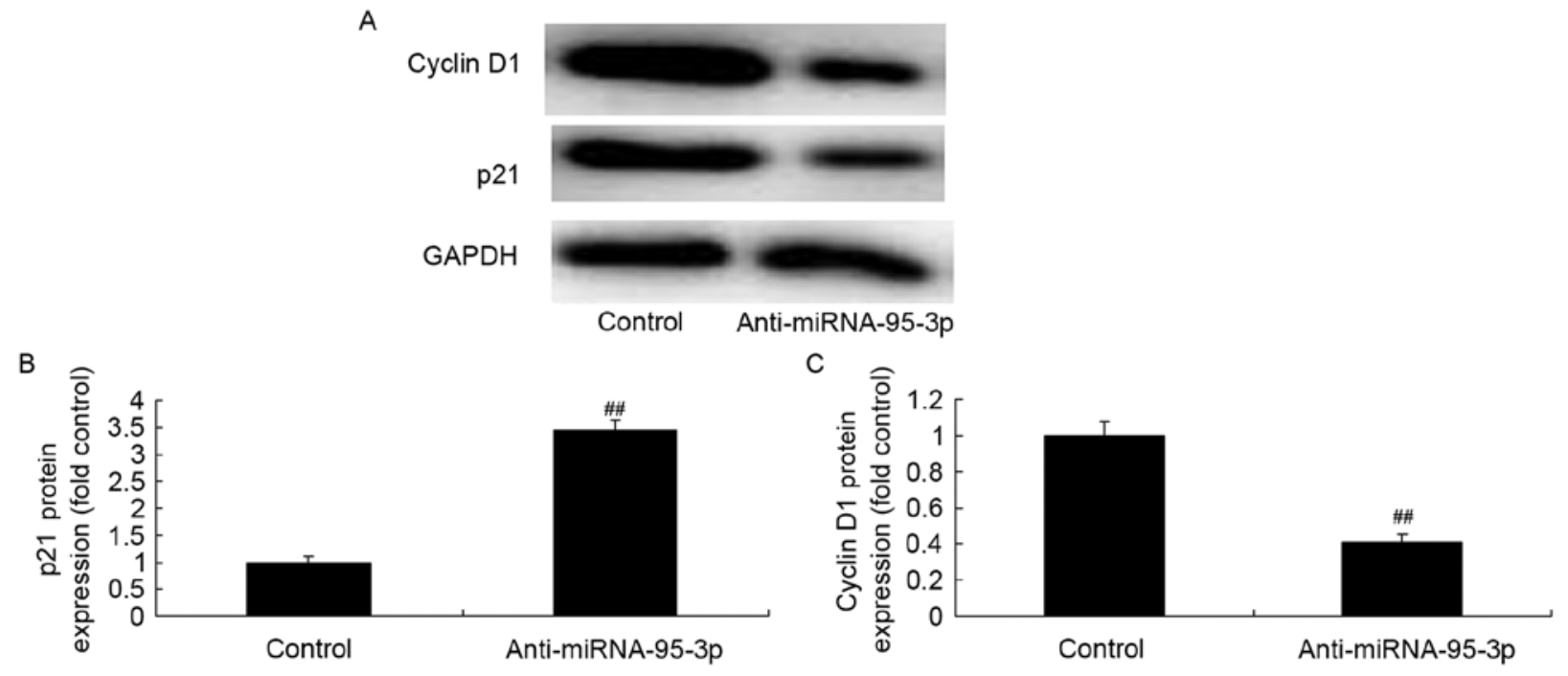

Figure 5. p21 and cyclin D1 protein expression of osteosarcoma cells by microRNA-95-3p downregulation. p21 and cyclin D1 protein expression by western blot assays (A) and statistical analysis of p21 and cyclin D1 protein expression (B and C). Control, control group; anti-microRNA-95-3p, anti-microRNA-95-3p mimics group. ${ }^{\# \#} \mathrm{P}<0.01$ compared with control group.

A

울
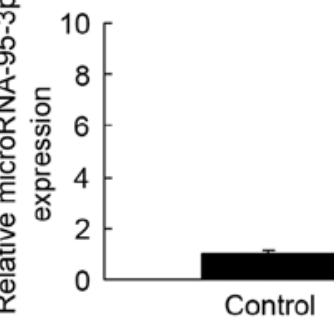

B
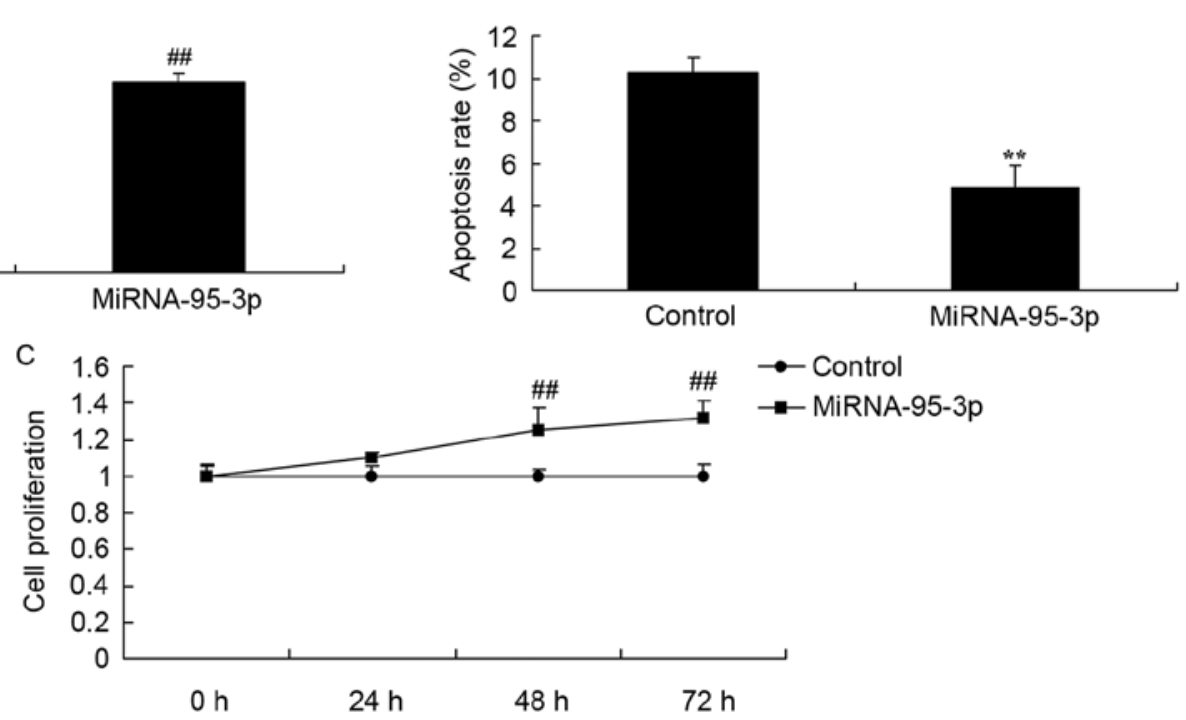

Figure 6. Cell growth and apoptosis of osteosarcoma cell by microRNA-95-3p overexpression. MicroRNA-95-3p expression (A), apoptosis rate (B), and cell growth (C). Control, control group; microRNA-95-3p, microRNA-95-3p mimics group. ${ }^{\# \#} \mathrm{P}<0.01$ compared with control group. ${ }^{* *} \mathrm{P}<0.01$.

we conducted western blotting in TGF- $\beta$ and $\operatorname{Smad} 2$ protein expression. As shown in Fig. 4, TGF- $\beta$ and Smad2 protein expression of osteosarcoma was significantly suppressed by microRNA-95-3p downregulation.

p21 and cyclin D1 protein expression of osteosarcoma cells by microRNA-95-3p downregulation. Then, we also found that microRNA-95-3p downregulation significantly reduced p21 and cyclin D1 protein expression of osteosarcoma in vitro (Fig. 5). Together, these data suggest that microRNA95-3p regulates death of osteosarcoma cells by CDKN1A/ p21 expression.

Cell growth and apoptosis of osteosarcoma cells by microRNA-95-3p overexpression. We determined whether the overexpression of microRNA-95-3p affects cell growth and apoptosis of osteosarcoma cells in vitro. Compared with control group, cell proliferation was increased and apoptosis was inhibited in osteosarcoma cells by microRNA-95-3p overexpression (Fig. 6).

Activity of caspase-3 and caspase-9 and Bax/Bcl-2 protein expression of osteosarcoma cells by microRNA-95-3p overexpression. To investigate the mechanism for apoptosis of osteosarcoma cells by microRNA-95-3p overexpression, we examined the activity of caspase- 3 and caspase- 9 and Bax/ Bcl-2 protein expression. As showed in Fig. 7, microRNA95-3p overexpression suppressed the activity of caspase-3 and caspase- 9 and $\mathrm{Bax} / \mathrm{Bcl}-2$ protein expression of osteosarcoma cells in vitro. 


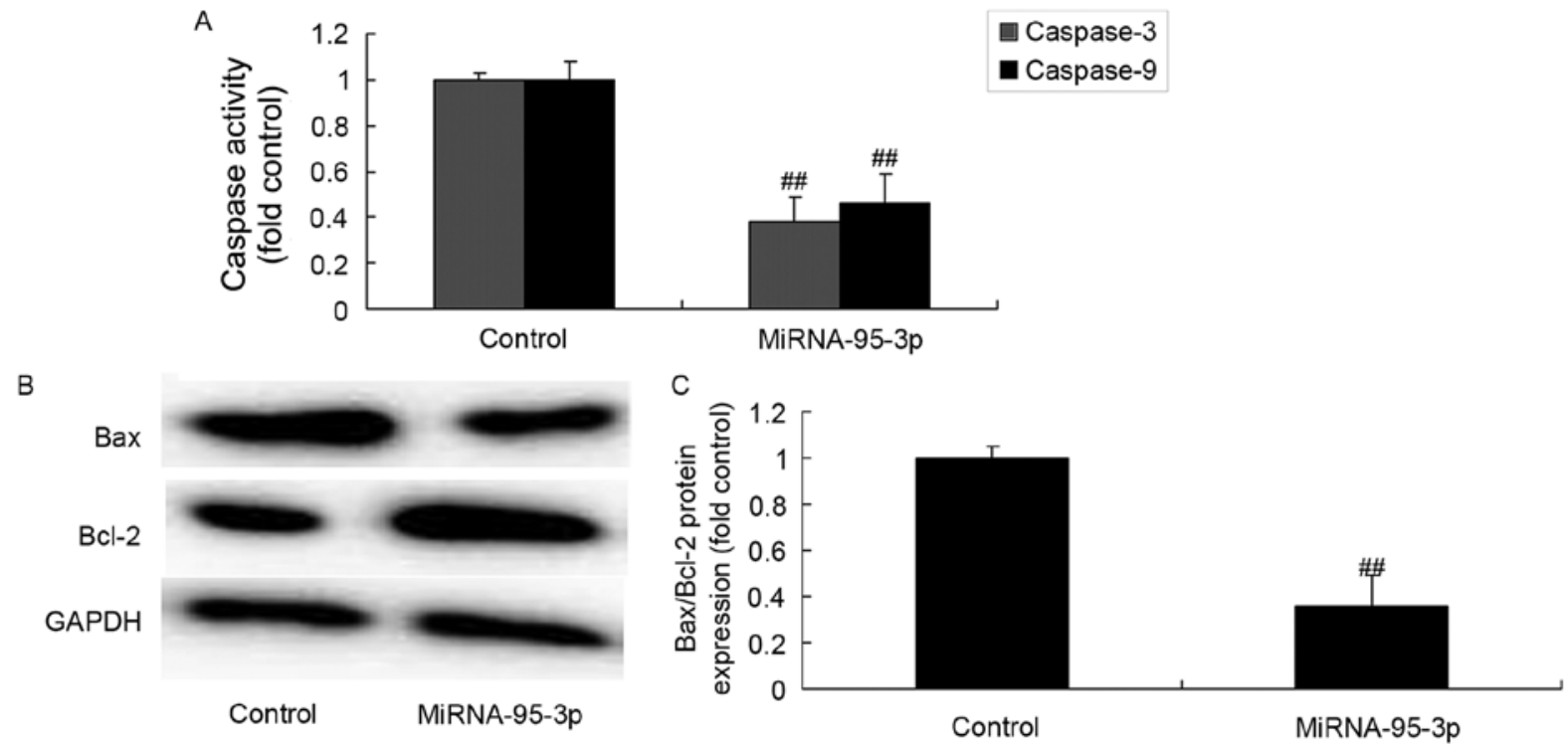

Figure 7. Activity of caspase-3 and caspase-9 and Bax/Bcl-2 protein expression of osteosarcoma cells by microRNA-95-3p overexpression. Caspase-3/9 activity (A) Bax/Bcl-2 protein expression by western blot assays (B) and statistical analysis of Bax/Bcl-2 protein expression (C). Control, control group; microRNA-95-3p, microRNA-95-3p mimics group. ${ }^{\# \#} \mathrm{P}<0.01$ compared with control group.

\section{A}
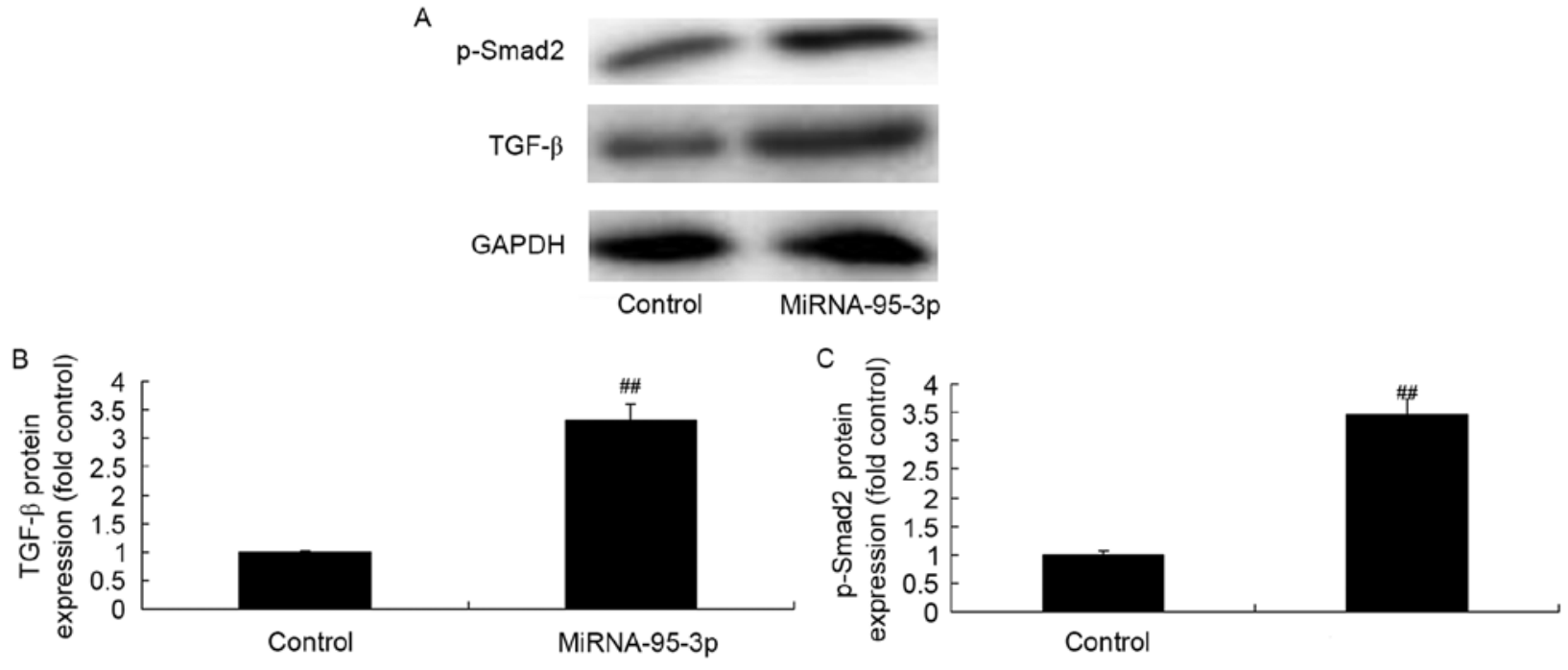

Figure 8 . TGF- $\beta$ and Smad 2 protein expression of osteosarcoma cells by microRNA-95-3p overexpression. TGF- $\beta$ and $p-S m a d 2$ protein expression by western blot assays (A) and statistical analysis of TGF- $\beta$ and p-Smad2 protein expression (B and C). Control, control group; microRNA-95-3p, microRNA-95-3p mimics group. ${ }^{\#} \mathrm{P}<0.01$ compared with control group.

TGF- $\beta$ and Smad2 protein expression of osteosarcoma cells by microRNA-95-3p overexpression. To check whether the decrease of microRNA-95-3p regulates TGF- $\beta$ and Smad2 protein expression of osteosarcoma cells, TGF- $\beta$ and Smad2 protein expression were determined by western blotting. TGF- $\beta$ and Smad 2 protein expression of osteosarcoma cells were significantly induced by microRNA-95-3p overexpression (Fig. 8).

p21 and cyclin D1 protein expression of osteosarcoma cell by microRNA-95-3p overexpression. To examine whether the observed effects of microRNA-95-3p are due to regulation of p21 and cyclin D1 protein expression, anti-microRNA-95-3p mimics were transfected into cells. p21 protein expression was significantly suppressed and cyclin D1 protein expression was also induced in osteosarcoma cells in vitro (Fig. 9). Together, microRNA-95-3p regulates $\mathrm{p} 21$ and cyclin D1 protein expression of osteosarcoma cells.

The promotion of TGF- $\beta$ on TGF- $\beta$ and Smad2 protein expression in osteosarcoma cells by microRNA-95-3p downregulation. To further validate the finding that microRNA-95-3p regulates TGF- $\beta$ expression, we examined the protein TGF- $\beta / \mathrm{Smad} 2$ expression. As shown in Fig. 10, TGF- $\beta$ expression promotion was significantly induced by TGF- $\beta$ and $p$-Smad 2 protein expression in osteosarcoma cells by microRNA-95-3p downregulation, as compared with microRNA-95-3p downregulation group. 
A
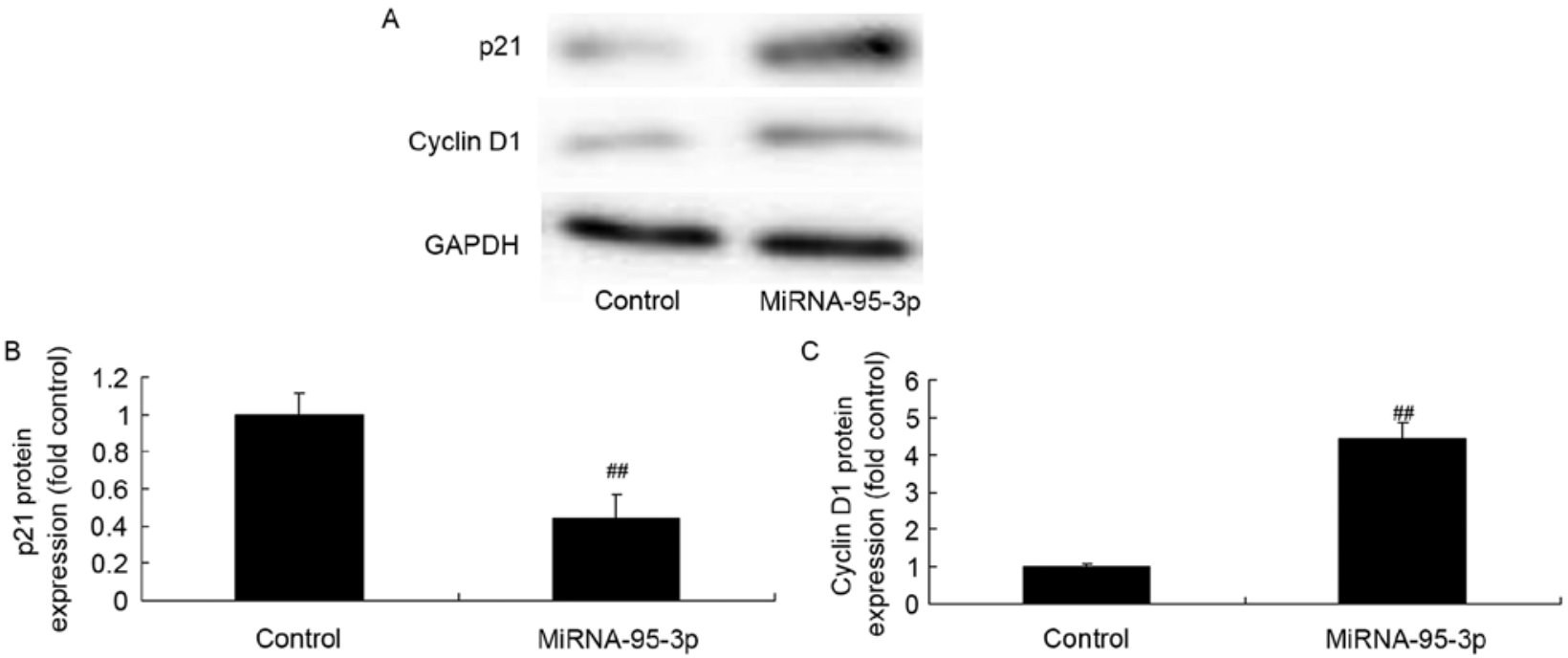

Figure 9. p21 and cyclin D1 protein expression of osteosarcoma cells by microRNA-95-3p overexpression. p21 and cyclin D1 protein expression by western blot assays (A) and statistical analysis of p21 and cyclin D1 protein expression (B and C). Control, control group; microRNA-95-3p, microRNA-95-3p mimics group. ${ }^{\# \#} \mathrm{P}<0.01$ compared with control group.

A
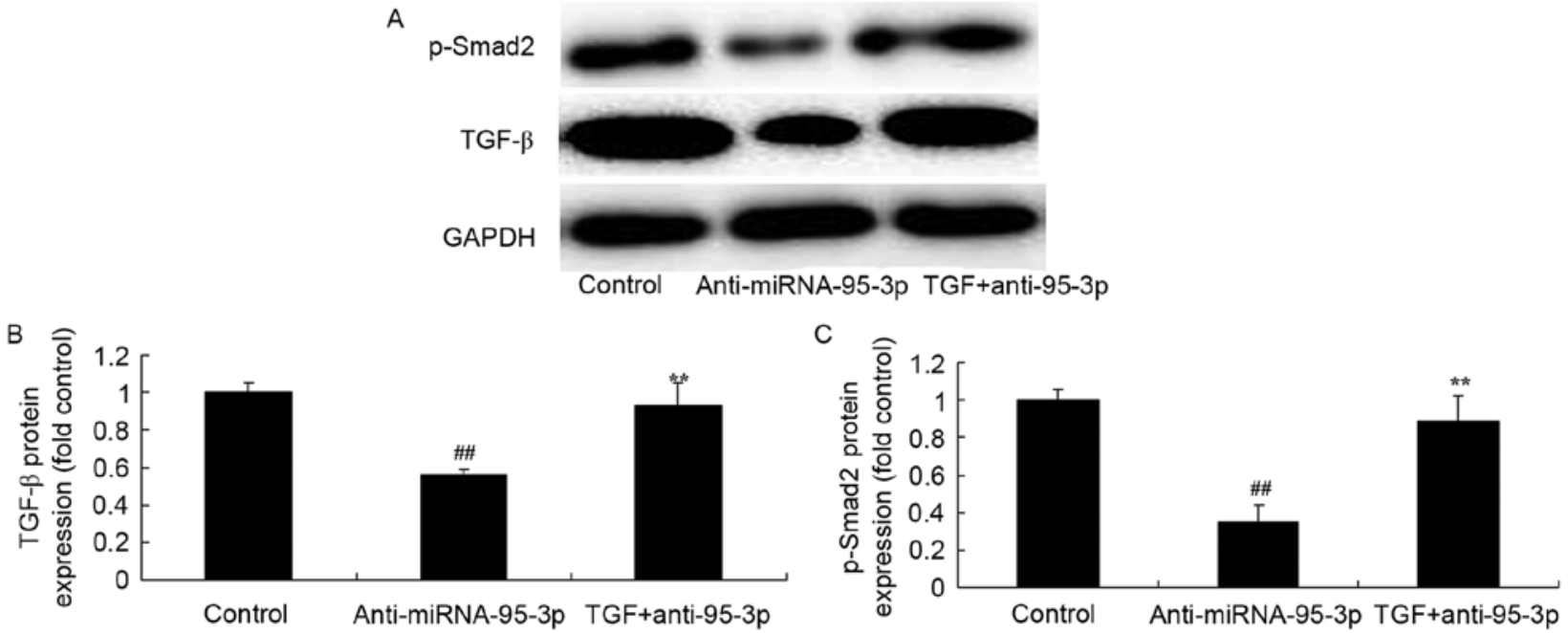

Figure 10. The promotion of TGF- $\beta$ on TGF- $\beta$ and Smad 2 protein expression in osteosarcoma cells by microRNA-95-3p downregulation. TGF- $\beta$ and p-Smad 2 protein expression by western blot assays (A) and statistical analysis of TGF- $\beta$ and p-Smad2 protein expression (B and C). Control, control group; anti-microRNA-95-3p, anti-microRNA-95-3p mimics group; TGF+anti-95-3p, anti-microRNA-95-3p mimics+TGF- $\beta$ group. ${ }^{\# \#} \mathrm{P}<0.01$ compared with control group, ${ }^{* *} \mathrm{P}<0.01$ compared with anti-microRNA-95-3p mimics group.

The promotion of TGF- $\beta$ on cell growth and apoptosis in osteosarcoma cells by microRNA-95-3p downregulation. Then, we found significant induction of cell growth and inhibition of apoptosis in osteosarcoma cells by microRNA-95-3p downregulation and TGF- $\beta$ promotion expression (Fig. 11).

The promotion of TGF- $\beta$ on caspase-3 and caspase-9 activities and Bax/Bcl-2 protein expression in osteosarcoma cells by microRNA-95-3p downregulation. To determine the impact of microRNA-95-3p on osteosarcoma apoptosis mechanism, TGF- $\beta$ and microRNA-95-3p mimics was transfected into F5M 2 cells. Furthermore, the promotion of TGF- $\beta$ led to inhibition of caspase- 3 and caspase- 9 activity and Bax/Bcl-2 protein expression in osteosarcoma cell by microRNA-95-3p downregulation (Fig. 12).
The promotion of TGF- $\beta$ on $p 21$ and cyclin D1 protein expression in osteosarcoma cells bymicroRNA-95-3p downregulation. The expression level of p21 and cyclin D1 was also assessed using western blotting. The results of western blotting showed that the p21 and cyclin D1 protein expression in osteosarcoma cells by microRNA-95-3p downregulation were significantly reversed by promotion of TGF- $\beta$ expression (Fig. 13).

\section{Discussion}

Osteosarcoma is the most common malignant osteogenic tumor with easy metastases, characterized by generation of osteoid matrix from tumor cells and constituted by sarcoma osteoblasts, osteoid tissue directly generated from osteoid tissue and new bones (10). In osteosarcoma, osteogenesis exists 
A

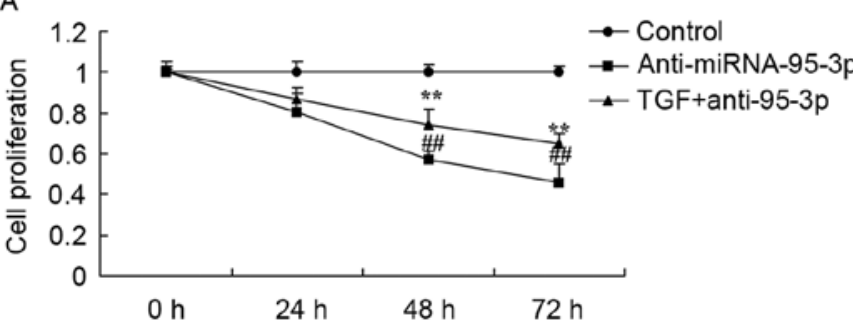

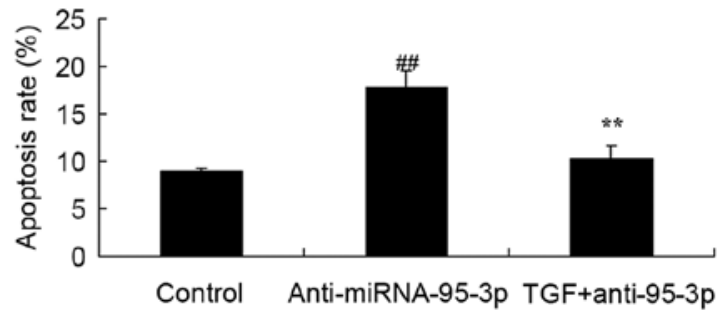

Figure 11. The promotion of TGF- $\beta$ on cell growth and apoptosis in osteosarcoma cells by microRNA-95-3p downregulation. Cell growth (A) and apoptosis rate (B). Control, control group; anti-microRNA-95-3p, anti-microRNA-95-3p mimics group; TGF+anti-95-3p, anti-microRNA-95-3p mimics+TGF- $\beta$ group. ${ }^{\# \#} \mathrm{P}<0.01$ compared with control group, ${ }^{* *} \mathrm{P}<0.01$ compared with anti-microRNA-95-3p mimics group.

A

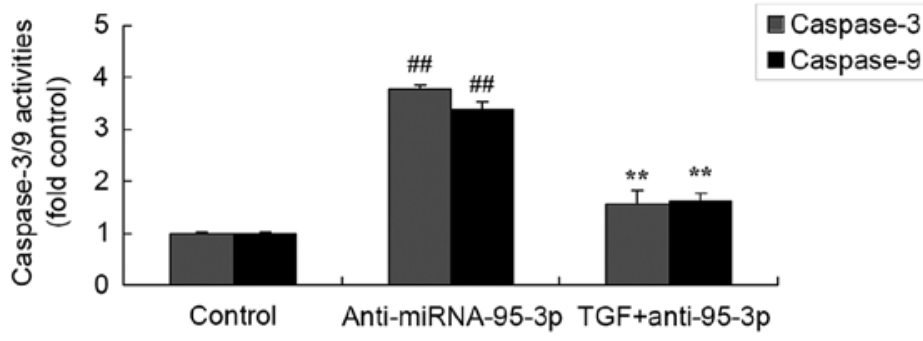

B

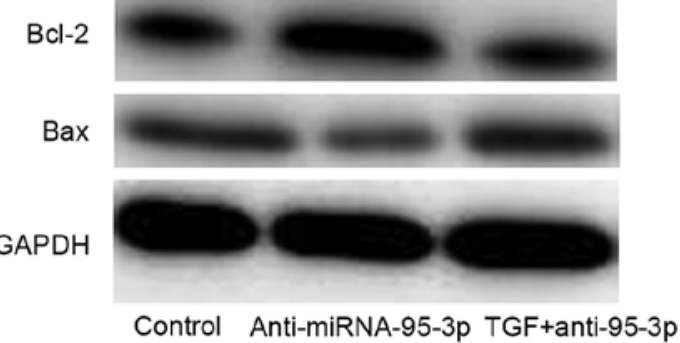

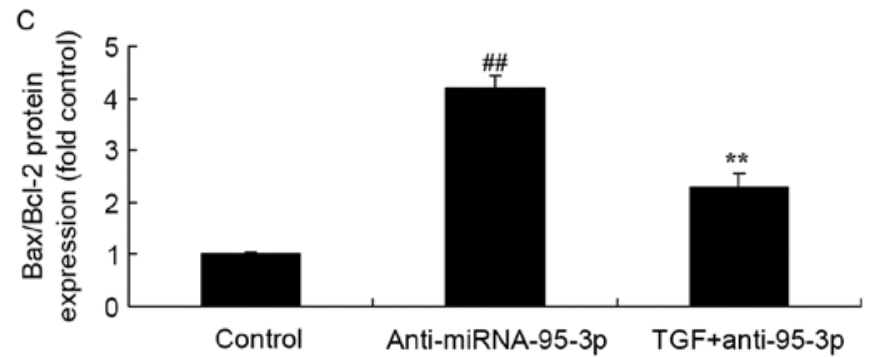

Figure 12. The promotion of TGF- $\beta$ on activity of caspase- 3 and caspase- 9 and Bax/Bcl-2 protein expression in osteosarcoma cells by microRNA-95-3p downregulation. Caspase-3/9 activity (A), Bax/Bcl-2 protein expression by western blot assays (B) and statistical analysis of Bax/Bcl-2 protein expression (C). Control, control group; anti-microRNA-95-3p, anti-microRNA-95-3p mimics group; TGF+anti-95-3p, anti-microRNA-95-3p mimics+TGF- $\beta$ group. ${ }^{\# \# ~} \mathrm{P}<0.01$ compared with control group, ${ }^{* *} \mathrm{P}<0.01$ compared with anti-microRNA-95-3p mimics group.
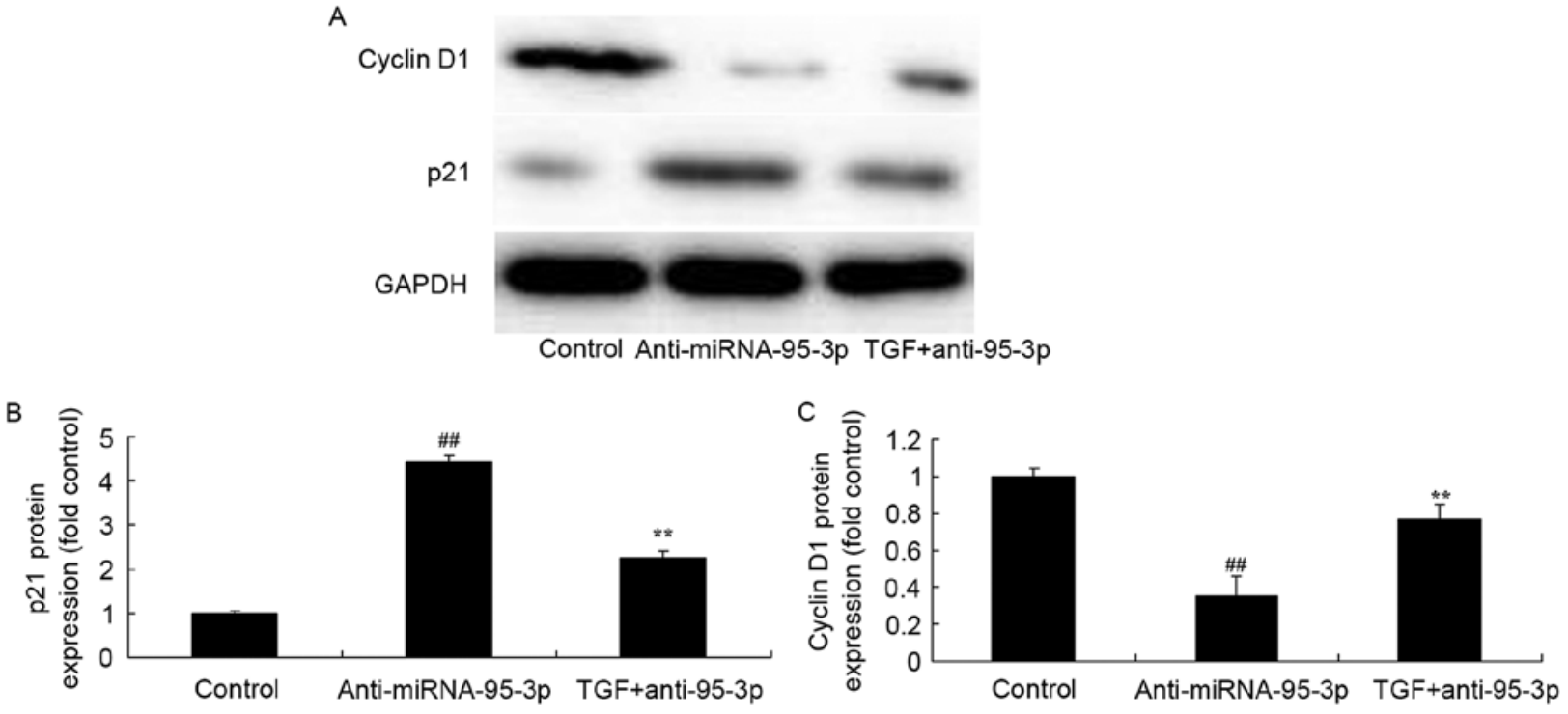

Figure 13. The promotion of TGF- $\beta$ on $\mathrm{p} 21$ and cyclin D1 protein expression in osteosarcoma cells by microRNA-95-3p downregulation. $\mathrm{p} 21$ and cyclin D1 protein expression by western blot assays (A) and statistical analysis of p21 and cyclin D1 protein expression (B and C). Control, control group; anti-microRNA-95-3p, anti-microRNA-95-3p mimics group; TGF+anti-95-3p, anti-microRNA-95-3p mimics+TGF- $\beta$ group. ${ }^{\# \#<0.01 ~ c o m p a r e d ~ w i t h ~ c o n t r o l ~}$ group, ${ }^{* *} \mathrm{P}<0.01$ compared with anti-microRNA-95-3p mimics group. 


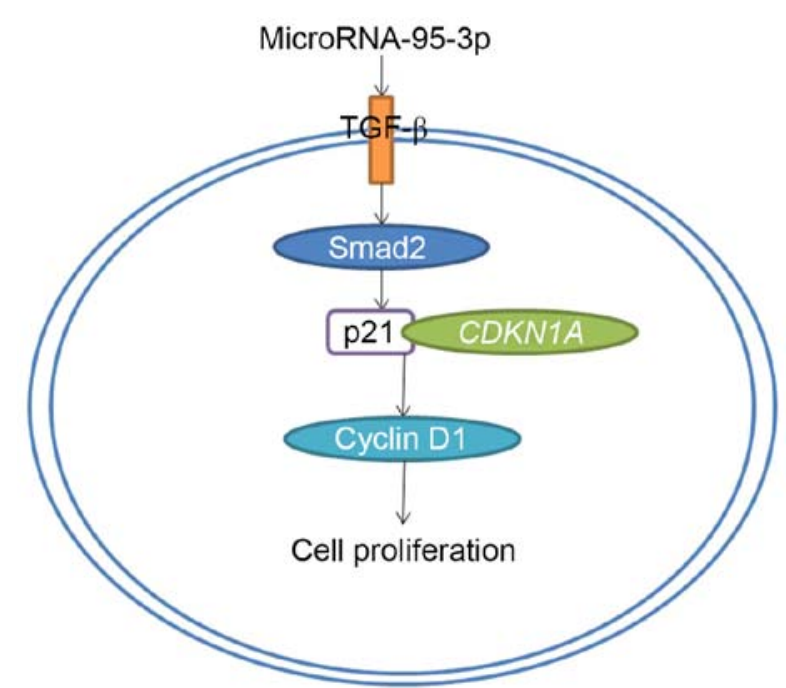

Figure 14. Downregulation of microRNA-95-3p expression suppresses cell growth of osteosarcoma via CDKN1A/p21 expression.

with osteoclasia at the same time, so it is classified into an osteoblastic type and an osteolytic type according to proportions of osteogenesis and osteoclasia (11). Osteosarcoma is highly malignant with extremely poor prognosis (12). Even when a therapeutic schedule combining surgery with chemotherapy is adopted, the five-year survival rate of patients is only 55-68\% (12). The main cause of the poor prognosis is that metastases occur in its early stage. As a result, the current anti-metastasis treatment cannot achieve a satisfactory effect (13). In addition, the large side-effect of systemic chemotherapy will damage various organs of human body to a certain degree and it is often hard for patients to accept severe impacts on their limb functions caused by surgical treatment (13). Hence, treatment of osteosarcoma has become a problem for researchers to solve urgently (3). We found that the serum expression of microRNA-95-3p was effectively upregulated in patients with osteosarcoma. Conversely, miR-95-3p expression in patients with osteosarcoma had significant association with clinical stage, which showed microRNA-95-3p may regulate osteosarcoma development and progression. Fan et al reported that the microRNA-95-3p downregulation inhibits proliferation and invasion promoting apoptosis of glioma cells (14).

miRNAs are a type of recently discovered non-coding microRNAs with a length of 22-28 nucleotides, which widely exist in eucaryon (5). By complete or partial complementary pairing with and binding to the target gene mRNA 3'-UTR, miRNAs cause degradation of target miRNA or translational suppression to regulate the expression of target genes, affecting biological behavior such as cell proliferation, invasion, differentiation and apoptosis (15). Unlike siRNAs, miRNAs have multiple target genes (15). As endogenous RNA interference is triggered, miRNAs regulate cells which are closer to a physiological level instead of regulation through a simple gene knockout (16). We found that downregulation of microRNA-95-3p expression suppresses cell growth, induced apoptosis, increased caspase- 3 and caspase- 9 activities and Bax protein expression in osteosarcoma cells; overexpression of microRNA-95-3p increased cell growth, and inhibited apoptosis of osteosarcoma cells, suggesting that microRNA95-3p has a potential benefit in osteosarcoma.

p21-activated kinase (PAK) proteins are evolutionarily conserved serine/threonine protein kinases which participate in regulation of biological functions such as cytoskeleton rearrangement, cell survival, cell apoptosis, angiogenesis and mitosis (15). p21 is a currently known as cell cyclin inhibition protein with the most extensive kinase inhibitory activity (17). Some scholars reported that positive expression rates of p21 in colon cancer and gastric cancer were 50.5 and 39\%, respectively, and research showed that the expression of p21 protein was related to tumorigenesis, tumor differentiation, invasion and metastases and clinical stages of tumors (18). In our results, downregulation of microRNA-95-3p expression induced $\mathrm{p} 21$ protein expression and overexpression of microRNA-95-3p suppressed p21 protein expression in osteosarcoma cells. Ye et al demonstrated that upregulation of miR-95-3p promotes tumorigenesis of hepatocellular cells via p21 expression (19).

TGF- $\beta /$ Smad promotes angiogenesis and strengthens interactions between tumor cells and extracellular matrix to enhance invasion and metastases of tumors mainly through immunosuppression/immune escape (20). New vessels of tumor cells are necessary for invasion and metastases of tumors and these vessels are immature vascular structures formed by endothelial cells falling off from mature vessels around the tumor with high permeability. Tumor cells permeate in the blood system, causing tumor metastases (21). TGF- $\beta /$ Smad can induce expression levels of angiogenic factors, such as VGEF and connective tissue growth factors (CTGFs), in epithelial cells and fibroblasts and expression, secretion and activation of matrix metalloproteinases, MMP-2 and MMP-9, in endothelial cells and tumor cells, leading to endothelial cell detachment from basement membranes (22). Our results demonstrate that downregulation of microRNA-95-3p expression suppressed TGF- $\beta$ and $p-S m a d 2$ protein expression, and overexpression of microRNA-95-3p induced TGF- $\beta$ and $p-S m a d 2$ protein expression in osteosarcoma cells. Taken together, our results demonstrate that microRNA-95-3p regulates TGF- $\beta / \mathrm{Smad} 2$ expression in osteosarcoma.

Gene p21waf1/cip1 is located on human chromosome $6 \mathrm{p} 21.2$ and $\mathrm{Mr}$ of the protein that it codes is $21 \times 10^{3}$. P21 has an extensive inhibiting effect on CDKs (cyclindependent kinases), especially on CDK2 and CDK4 (23). The Cyclin-CDK complex is a positive regulatory factor in the cell cycle, called the engine of cell cycles, and can help cells quickly pass checkpoints of the cell cycles (23). Its overexpression can reduce cell mass and promote proliferation and transformation. P21waf $1 /$ cip1 plays a role of checkpoint control in inhibition of Cyclin-CDK (24). Cyclin D1 is cell cycle protein synthesized from early G1 phase and reaching its peak during middle G1 phase $(7,25)$. It promotes cells to enter $\mathrm{S}$ phase from $\mathrm{G} 1$ phase and overexpression of cyclin D1 can shorten G1 phase and make cells step into S phase from G1 phase in advance, resulting in uncontrolled growth, transformation and cancerization of cells (26). In our experiments, TGF- $\beta$ promotion reversed the anticancer effects of microRNA-95-3p on osteosarcoma cells through p21/cyclin D1 expression. Hwang et al reported that 
microRNA-95-3p overexpression reduced brain metastasis of lung adenocarcinoma via cyclin D1 expression (27).

In summary, we have found that the serum expression of microRNA-95-3p was effectively upregulated in patients with osteosarcoma. Downregulation of microRNA-95-3p expression suppresses cell growth, induced apoptosis, increased caspase- 3 and caspase- 9 activities and $\mathrm{Bax} / \mathrm{Bcl}-2$ protein expression in osteosarcoma cell through TGF- $\beta / \mathrm{CDKN} 1 \mathrm{~A} /$ p21/cyclin D1 expression (Fig. 14). This study established microRNA-95-3p as a potential biomarker for diagnosis of osteosarcoma through TGF- $\beta / C D K N 1 A / p 21 /$ cyclin D1 expression and as a new therapeutic target for prevention and treatment of osteosarcoma.

\section{References}

1. Ebb D, Meyers P, Grier H, Bernstein M, Gorlick R, Lipshultz SE, Krailo M, Devidas M, Barkauskas DA, Siegal GP, et al: Phase II trial of trastuzumab in combination with cytotoxic chemotherapy for treatment of metastatic osteosarcoma with human epidermal growth factor receptor 2 overexpression: A report from the children's oncology group. J Clin Oncol 30: 2545-2551, 2012.

2. Li J, Guo Z, Wang Z, Fan $\mathrm{H}$ and Fu J: Does microwave ablation of the tumor edge allow for joint-sparing surgery in patients with osteosarcoma of the proximal tibia? Clin Orthop Relat Res 473: 3204-3211, 2015

3. Bajpai J, Gamanagatti S, Sharma MC, Kumar R, Vishnubhatla S, Khan SA, Rastogi S, Malhotra A and Bakhshi S: Noninvasive imaging surrogate of angiogenesis in osteosarcoma. Pediatr Blood Cancer 54: 526-531, 2010.

4. Bacci G, Ferrari S, Longhi A, Picci P, Mercuri M, Alvegard TA, Saeter G, Donati D, Manfrini M, Lari S, et al; Italian Sarcoma Group/Scandinavian Sarcoma Group: High dose ifosfamide in combination with high dose methotrexate, adriamycin and cisplatin in the neoadjuvant treatment of extremity osteosarcoma: Preliminary results of an Italian Sarcoma Group/Scandinavian Sarcoma Group pilot study. J Chemother 14: 198-206, 2002.

5. Wang X, Ning Y, Yang L, Liu H, Wu C, Wang S and Guo X: Diagnostic value of circulating microRNAs for osteosarcoma in Asian populations: A meta-analysis. Clin Exp Med 17: 175-183, 2017.

6. Chen R, Li X, He B and Hu W: MicroRNA-410 regulates autophagy-related gene ATG16L1 expression and enhances chemosensitivity via autophagy inhibition in osteosarcoma. Mol Med Rep 15: 1326-1334, 2017.

7. Shang Y, Wang LQ, Guo QY and Shi TL: MicroRNA-196a overexpression promotes cell proliferation and inhibits cell apoptosis through PTEN/Akt/FOXO1 pathway. Int J Clin Exp Pathol 8: 2461-2472, 2015.

8. Han K, Zhou Y, Gan ZH, Qi WX, Zhang JJ, Fen T, Meng W, Jiang L, Shen Z and Min DL: p21-activated kinase 7 is an oncogene in human osteosarcoma. Cell Biol Int 38: 1394-1402, 2014.

9. Zhang X, Ma W, Cui J, Yao H, Zhou H, Ge Y, Xiao L, Hu X, Liu BH, Yang J, et al: Regulation of p21 by TWIST2 contributes to its tumor-suppressor function in human acute myeloid leukemia. Oncogene 34: 3000-3010, 2015.

10. Pappo AS, Vassal G, Crowley JJ, Bolejack V, Hogendoorn PC, Chugh R, Ladanyi M, Grippo JF, Dall G, Staddon AP, et al: A phase 2 trial of R1507, a monoclonal antibody to the insulin-like growth factor-1 receptor (IGF-1R), in patients with recurrent or refractory rhabdomyosarcoma, osteosarcoma, synovial sarcoma, and other soft tissue sarcomas: Results of a Sarcoma Alliance for Research Through Collaboration study. Cancer 120: 2448-2456, 2014.
11. Kudawara I, Aoki Y, Ueda T, Araki N, Naka N, Nakanishi H, Matsumine A, Ieguchi M, Mori S, Myoui A, et al: Neoadjuvant and adjuvant chemotherapy with high-dose ifosfamide, doxorubicin, cisplatin and high-dose methotrexate in non-metastatic osteosarcoma of the extremities: A phase II trial in Japan. J Chemother 25: 41-48, 2013.

12. Grignani G, Palmerini E, Ferraresi V, D'Ambrosio L, Bertulli R, Asaftei SD, Tamburini A, Pignochino Y, Sangiolo D, Marchesi E, et al; Italian Sarcoma Group: Sorafenib and everolimus for patients with unresectable high-grade osteosarcoma progressing after standard treatment: A non-randomised phase 2 clinical trial. Lancet Oncol 16: 98-107, 2015

13. den Hengst WA, Hendriks JM, Balduyck B, Rodrigus I, Vermorken JB, Lardon F, Versteegh MI, Braun J, Gelderblom H, Schramel FM, et al: Phase II multicenter clinical trial of pulmonary metastasectomy and isolated lung perfusion with melphalan in patients with resectable lung metastases. J Thorac Oncol 9: 1547-1553, 2014.

14. Fan B, Jiao BH, Fan FS, Lu SK, Song J, Guo CY, Yang JK and Yang L: Downregulation of miR-95-3p inhibits proliferation, and invasion promoting apoptosis of glioma cells by targeting CELF2. Int J Oncol 47: 1025-1033, 2015.

15. Sampson VB, Yoo S, Kumar A, Vetter NS and Kolb EA: MicroRNAs and potential targets in osteosarcoma: Review. Front Pediatr 3: 69, 2015.

16. Wang Z, He R, Xia H, Wei YU and Wu S: MicroRNA-101 has a suppressive role in osteosarcoma cells through the targeting of c-FOS. Exp Ther Med 11: 1293-1299, 2016.

17. Xu M, Xie Y, Sheng W, Miao J and Yang J: Adenovirus-mediated ING4 gene transfer in osteosarcoma suppresses tumor growth via induction of apoptosis and inhibition of tumor angiogenesis. Technol Cancer Res Treat 14: 369-378, 2015.

18. Yong ST and Wang XF: A novel, non-apoptotic role for Scythe/ BAT3: A functional switch between the pro- and anti-proliferative roles of p21 during the cell cycle. PLoS One 7: e38085, 2012.

19. Ye J, Yao Y, Song Q, Li S, Hu Z, Yu Y, Hu C, Da X, Li H, Chen Q, et al: Up-regulation of miR-95-3p in hepatocellular carcinoma promotes tumorigenesis by targeting p21 expression. Sci Rep 6: 34034, 2016.

20. Kim BG,Lee JH, Yasuda J, Ryoo HM and Cho JY: Phospho-Smad1 modulation by nedd4 E3 ligase in BMP/TGF- $\beta$ signaling. J Bone Miner Res 26: 1411-1424, 2011.

21. Navid F, Letterio JJ, Yeung CL, Pegtel M and Helman LJ: Autocrine transforming growth factor-beta growth pathway in murine osteosarcoma cell lines associated with inability to affect phosphorylation of retinoblastoma protein. Sarcoma 4: 93-102, 2000 .

22. Li F, Li S and Cheng T: TGF- $\beta 1$ promotes osteosarcoma cell migration and invasion through the miR-143-versican pathway. Cell Physiol Biochem 34: 2169-2179, 2014.

23. Chow LT: Giant cell rich osteosarcoma revisited-diagnostic criteria and histopathologic patterns, Ki67, CDK4, and MDM2 expression, changes in response to bisphosphonate and denosumab treatment. Virchows Arch 468: 741-755, 2016.

24. Benassi MS, Molendini L, Gamberi G, Ragazzini P, Sollazzo MR, Merli M, Asp J, Magagnoli G, Balladelli A, Bertoni F, et al: Alteration of $\mathrm{pRb} / \mathrm{p} 16 / \mathrm{cdk} 4$ regulation in human osteosarcoma. Int J Cancer 84: 489-493, 1999.

25. Zhang C, Zhao Y and Zeng B: Enhanced chemosensitivity by simultaneously inhibiting cell cycle progression and promoting apoptosis of drug-resistant osteosarcoma MG63/DXR cells by targeting cyclin D1 and Bcl-2. Cancer Biomark 12: 155-167, 2012.

26. Wang J, Ni J, Yi S, Song D and Ding M: Protein inhibitor of activated STAT $\mathrm{x} \alpha$ depresses cyclin D and cyclin D kinase, and contributes to the inhibition of osteosarcoma cell progression. Mol Med Rep 13: 1645-1652, 2016.

27. Hwang SJ, Lee HW, Kim HR, Song HJ, Lee DH, Lee H, Shin CH, Joung JG, Kim DH, Joo KM, et al: Overexpression of microRNA-95-3p suppresses brain metastasis of lung adenocarcinoma through downregulation of cyclin D1. Oncotarget 6: 20434-20448, 2015. 